\title{
An Experimental Study on the H-Beam Under Fire Load in Open Space
}

\author{
Min Suk Ki®1, Beom Jin Park®1, Kangsu Lee ${ }^{\circledR 2}$, \\ Byoungjae Park ${ }^{\circledR 1}$, Kyle Fernandez ${ }^{3}$ and In Sik Nho ${ }^{(4}$ \\ ${ }^{1}$ Senior Researcher, Korea Research Institute of Ships and Ocean Engineering, Daejeon, Korea \\ ${ }^{2}$ Principle Researcher, Korea Research Institute of Ships and Ocean Engineering, Daejeon, Korea \\ ${ }^{3}$ Engineer, Southwest Research Institute, San Antonio, USA \\ ${ }^{4}$ Professor, Chungnam National University, Daejeon, Korea
}

KEY WORDS: Fire experiment, Displacement measurement, Gas temperature measurement, Steel surface temperature measurement, Burner fire

\begin{abstract}
To validate the fire safety assessment of structures, many structural experiments under fire load have been conducted. However, most of these experiments were conducted in restricted environments, such as inside a furnace, and experiments were seldom carried out in open space. In this study, an experimental study on H-beams, frequently used as structural reinforcements, was carried out for validating the thermal-structural analysis method under development. A $1.8 \mathrm{MW}$ burner fire was adopted with each end of the H-beam fixed without a mechanical load. Gas temperature, steel surface temperature, and displacements were then measured. During the experiment, gas and steel temperatures were obtained at 9 and 17 points near the H-beam, respectively. In addition, the vertical and horizontal displacements of the H-beam under fire load at 6 points were obtained. Furthermore, it was verified that the stable displacement measurements via the contact and non-contact methods were feasible in harsh environments where flames and smoke were both present.
\end{abstract}

\section{Introduction}

The fire safety assessment procedure of ships and offshore structures can be briefly described as a procedure for assessing safety by defining fire loads according to accident scenarios and analyzing their effects on the structure. In general, safety is reviewed via the temperature criteria of the structures under fire loads, and it is assessed in more detail via thermal-structural analysis, which combines fire simulation-heat transfer analysis with structural analysis in the design stage. Therefore, the accuracy of the thermal-structural analysis is crucial for reliable fire safety assessment, and the most applied method for validating the accuracy is to compare with the experimental results. Although fire experiments have been conducted by many researchers to analyze the characteristics of flames and heat transfer of steel members, constructing the temperature-dependent material property data, verifying the fire resistance performance of the structure itself, developing and validating numerical models, including other experiments have been conducted from the perspective of fluids with a primary focus on measuring gas and steel surface temperatures. On the other hand, fire experiments from the perspective of structure, which measure the displacement of a structure under fire load, were conducted mainly in limited environments such as inside a furnace because it was difficult to measure displacement in a high-temperature environment with a mixture of flames and smoke, as well as controlling the heat of the fire source. In addition, fire experiments conducted in open space have been seldom carried out. The British Steel Corporation (BSC) has summarized standard fire experiment results for structures such as steel beams and columns (Wainman and Kirby, 1988; Wainman et al., 1990). Cong conducted a furnace fire experiment on an I-beam, which is widely used as structural members for offshore structures, under mechanical loads to measure the steel surface temperature and vertical displacement. The vertical displacement was then measured by linear variable differential transformers (LVDTs) installed on top of the specimen exposed to the exterior parts of the furnace (Cong et al., 2005). The results obtained from this experiment have been widely used by other researchers to develop numerical analysis techniques (Kim, 2014; Kim et al., 2017). In addition to steel, fire experiments have also been conducted on sandwich panel structures made of fiber-reinforced plastic (FRP) (Rahm et al., 2017). However, the aforementioned experiments were

Received 4 October 2020, revised 28 December 2020, accepted 31 December 2020

Corresponding author In Sik Nho: +82-42-821-6622, isnho@cnu.ac.kr

(C) 2021, The Korean Society of Ocean Engineers

This is an open access article distributed under the terms of the creative commons attribution non-commercial license (http://creativecommons.org/licenses/by-nc/4.0) which permits unrestricted non-commercial use, distribution, and reproduction in any medium, provided the original work is properly cited. 
all conducted inside a furnace. Although the furnace fire experiment has the advantage of a constant temperature maintained inside the furnace, it is limited because technically, it cannot be used to validate the thermal-structural analysis technology for fire safety assessment owing to the fact that it is unnecessary to conduct fire simulation.

The most widely used method of measuring displacement during fire experiments is using LVDTs. However, LVDTs are difficult to use in high-temperature environment with a mixture of flames and smoke, because they should be installed and used mainly on the non-heated surfaces of the target structure. Efforts are also continuously being made to address this limitation. Choe measured the displacement of a steel beam under local fire load using a specially manufactured potentiometer (Choe et al., 2016), and Hodges evaluated the fire resistance performance of aluminum beams under fire and mechanical loads via thermographic digital image correlation (TDIC) (Hodges et al., 2016). Similarly, studies are being conducted to measure displacement in environments where high-temperature flames and smoke are mixed. The studies on displacement measurement are being conducted towards the application of an insulated extension cable, in the case of adopting contact-type equipment, as well as developing and verifying a method that adopts imaging equipment when using non-contact equipment.

In this study, a fire experiment was conducted on the H-beam, which is a structural reinforcement that is widely used in ships and offshore structures, to obtain data for validating the thermal-structural analysis technology. A burner fire, which is numerically easy to implement and control was used as the fire source. Consequently, gas temperature, steel surface temperature, and displacement were measured and the results obtained were analyzed. In particular, displacement was determined by measuring the vertical and horizontal displacements using a string potentiometer with extension cable insulated with flexible fire resistant hose, to observe the load path owing to the fire in the time domain.

\section{Burner Fire Experiment}

Burner fire experiment was conducted at a fire testing facility of the Southwest Research Institute (SwRI), which was established in 1947 and has extensive experience in the field of fire engineering. The size of the fire testing facility is approximately $18 \mathrm{~m} \times 12 \mathrm{~m} \times 12 \mathrm{~m}$, and
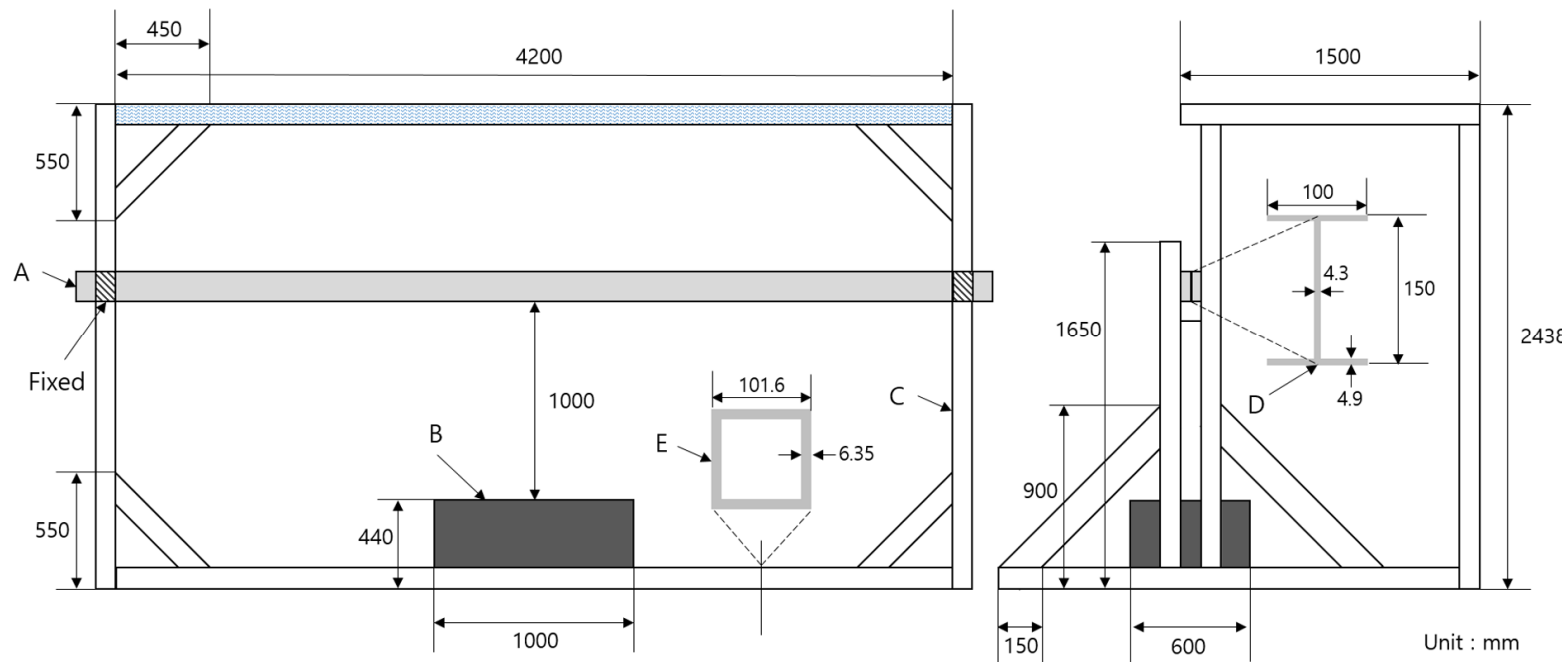

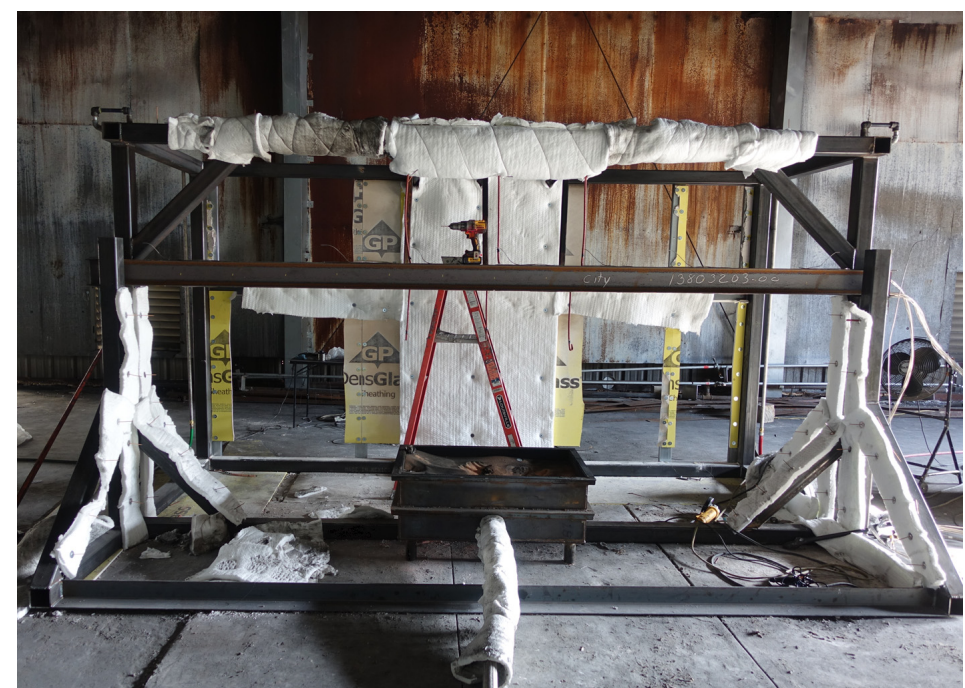

(a) Front view

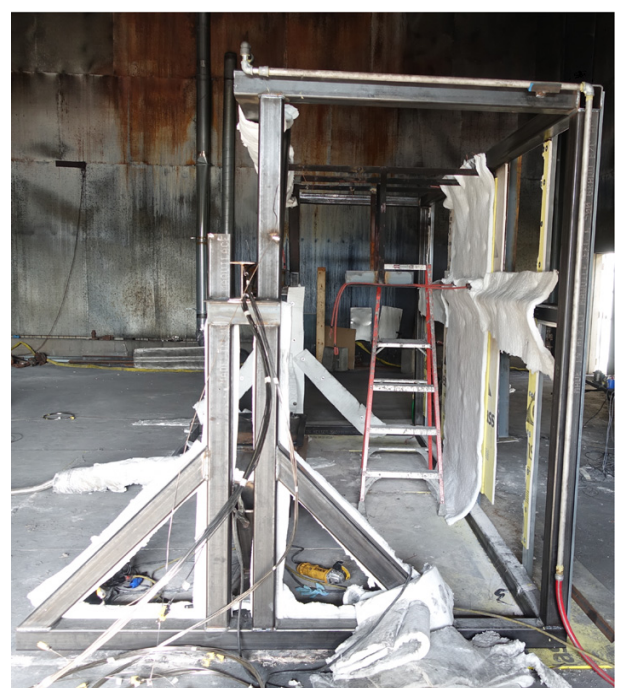

(b) Side view

Fig. 1 Test setup 
ventilation openings were installed on the ceiling. The room temperature was $38{ }^{\circ} \mathrm{C}$ during the experiment and the experiment was setup as illustrated in Fig. 1.

\subsection{Target Structure}

An H-beam (A in Fig. 1, ASTM A992, $\sigma_{y}=413 \mathrm{MPa}$ ), which is the target structure for the burner fire experiment, was installed on the manufactured support (C in Fig. 1, ASTM A500 grade B, $\sigma_{y}=315$ $\mathrm{MPa})$. The designation of the specimen was ASTM W6 $\times 4$, and its cross-sectional specifications are represented by D in Fig. 1, where the lengths of the specimen and flame exposure were 4,600 and 4,200 mm, respectively. The injected molded specimen was used without alterations to minimize the heat effect from cutting and welding. A part of the support exposed to the flame was insulated using ceramic wool, which is an insulating material; in particular, water was injected into the upper part of the support and circulated to minimize the effect of high temperatures on the support. The cross section of the support is as represented by E in Fig. 1.

\subsection{Experimental Conditions}

A 1.8 MW burner fire was as the fire source. To implement a uniform fire, a sand diffused propane burner (B in Fig. 1) with dimensions of $600 \mathrm{~mm} \times 1,000 \mathrm{~mm} \times 440 \mathrm{~mm}$ was installed at a position $1,000 \mathrm{~mm}$ away from the lower center of the specimen. The target heat release rate of $1.8 \mathrm{MW}$ was maintained by providing uniform flow of propane gas to the sand diffused burner verified with a Coriolis mass flow meter, as illustrated in Fig. 2. The target heat release rate was calculated as the product of the fuel flow rate and effective heat of combustion, as expressed in Eq. (1). The total combustion time was $3,600 \mathrm{~s}$.

$$
\dot{Q}=\dot{m} \Delta H_{c, e f f}
$$

where $\dot{Q}, \dot{m}$, and $\Delta H_{c, e f f}$ represent the target heat release rate

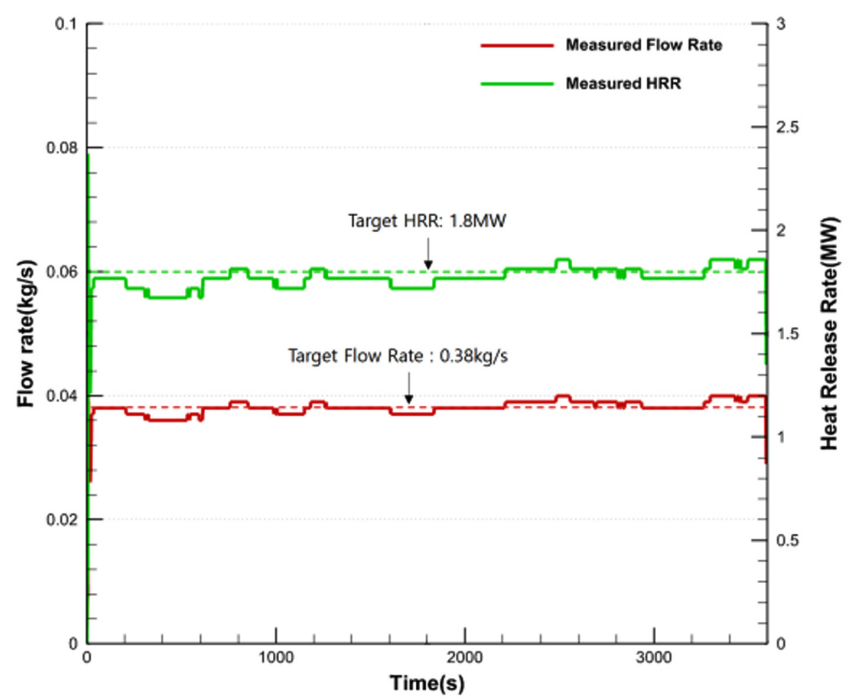

Fig. 2 Measured propane flow rate and calculated heat release rate

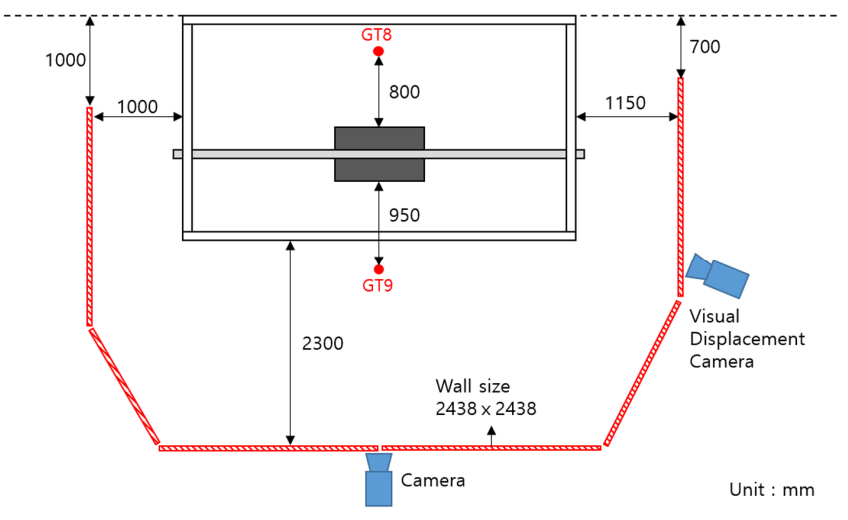

Fig. 3 Location of wind shield walls

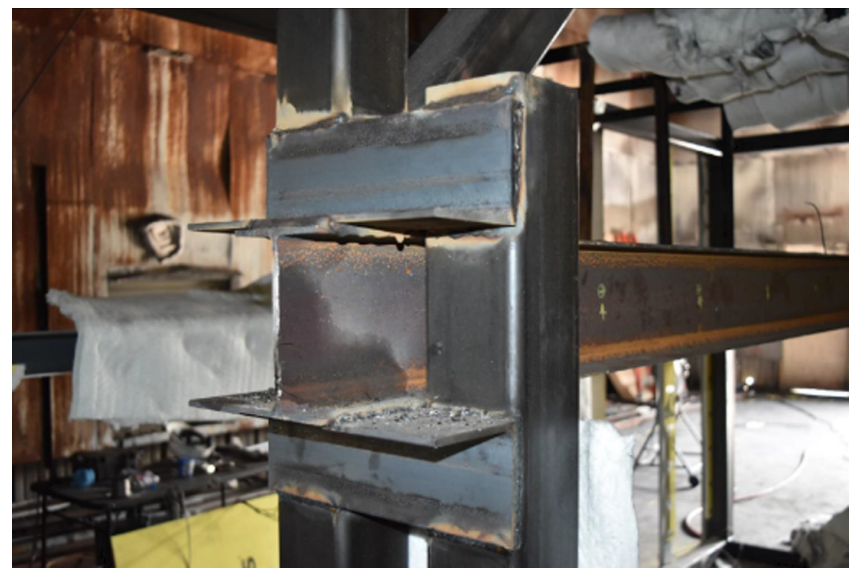

Fig. 4 Fixed end of specimen welded along all edges of both flanges

(MW), target flow rate of fuel $(\mathrm{kg} / \mathrm{s})$, and effective heat of combustion $(\mathrm{MJ} / \mathrm{kg})$ of the fuel, respectively. In this study, the experiment was conducted by setting the target heat release and target flow rates at 1.8 MW and $0.38 \mathrm{~kg} / \mathrm{s}$, respectively, by using $46.5 \mathrm{MJ} / \mathrm{kg}$ of propane's effective heat of combustion.

A significant flame movement was observed when a preliminary experiment was conducted to determine the stability of the burner fire. Therefore, to minimize flame movement and prevent damage to the measurement instrument owing to high temperature, wind shield walls were installed, as shown in Fig. 3. In addition, the experiment was conducted by fixing both ends of the specimen to the support without mechanical load to solely examine the effects of the fire load and boundary conditions triggered by the burner fire. The boundary conditions for fixing both ends of the specimen were implemented via a method that involves welding the contacts by positioning the specimen between the supports and installing an angle, as illustrated in Fig. 4.

\subsection{Measured Data}

Fig. 5 presents the measurement positions of the gas temperature, steel surface temperature, and displacement in the fire experiment while the actual instruments installed are illustrated in Fig. 6. Figs. 6(a) and (b) show the thermocouples adopted for measuring gas and 


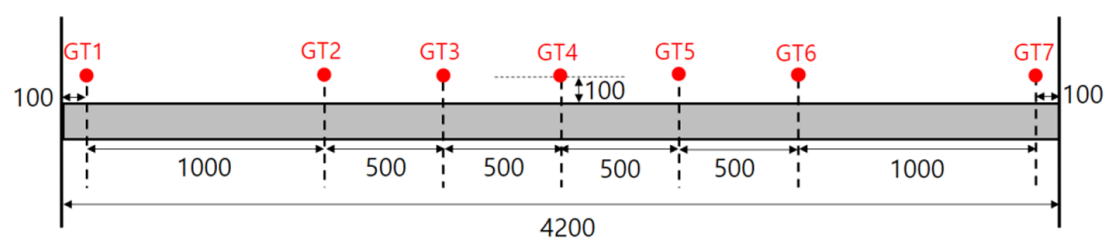

(a) Gas temperature

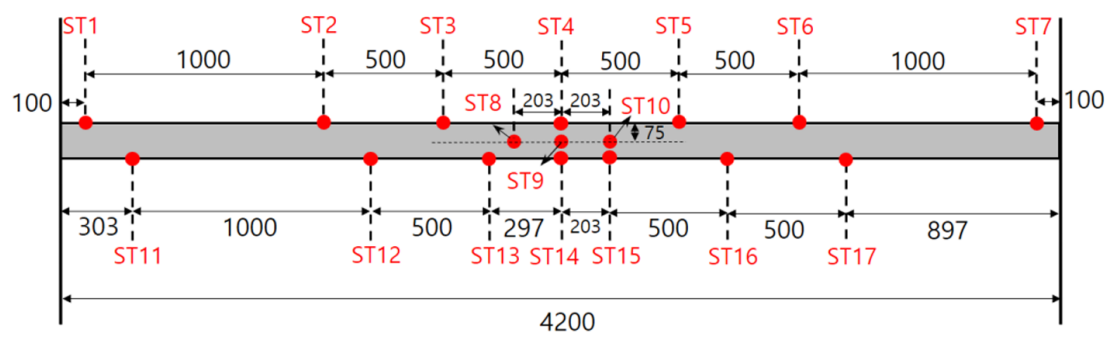

(b) Steel surface temperature

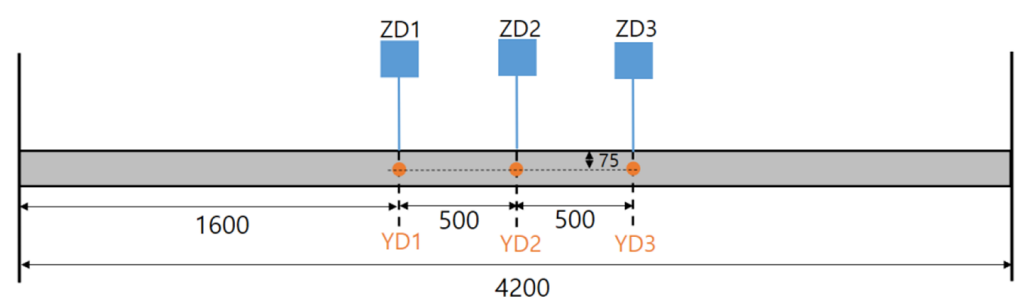

(c) Displacement

Fig. 5 Measurement positions of burner fire experiment

steel surface temperatures, respectively. The installations of the measuring instruments for vertical and horizontal displacements are illustrated in Figs. 6(c), (d), (e) and (f), respectively.

Gas temperature was measured by installing thermocouples at 7 points, $100 \mathrm{~mm}$ away from the upper flange of the specimen, as shown in Figs. 5(a), and 950 and $800 \mathrm{~mm}$ away from the specimen in the width direction (see Fig. 3), respectively, to observe the gas temperature distribution in the longitudinal direction of the specimen. To observe the specimen's steel surface temperature distribution owing to the flame, the steel surface temperature was measured by installing thermocouples at 14 points along upper and lower flanges, as well as 3 points on web, as shown in Fig. 5(b). In the upper flange case, the steel surface temperature was measured at the same position as that of the gas temperature measurement in the longitudinal direction of the specimen to observe the trend of the gas and steel surface temperatures. In the web case, a thermocouple was installed primarily in the center of the specimen where the flame was expected to be concentrated to observe the distribution of temperature in the horizontal and vertical directions of the specimen center. In the lower flange case, the steel surface temperature between the measurement positions of the upper flange steel surface temperature was measured to thoroughly observe the temperature distribution in the longitudinal direction of the specimen. To minimize the heat flow effect that may be triggered by the volume of the sensor line insulation, an Inconel-sheathed grounded-junction type " $\mathrm{K}$ " thermocouple without insulation requirements was adopted as the thermocouple.
To measure the vertical and horizontal displacements owing to the fire load on the specimen, a string potentiometer was installed behind the wind shield walls, and the extension cables were installed at 3 points along upper flange and 3 points along web, as shown in Figs. 6(f) and 5(c), respectively. The extension cable was insulated using a flexible fire resistance hose to minimize direct exposure to the flame. In addition, we attempted to separate the thermocouple from the displacement measurement extension cable by installing a support, where the measurement positions of the steel surface temperatures and displacement overlap, as illustrated in Fig. 6(c). The size of the support was reduced to minimize the possible effect of heat transfer on the steel surface. In particular, pipes and supports were installed, as illustrated in Figs. 6(d) and (e), to prevent the deflection of the extension cable and flexible fire resistance hose of the horizontal displacement measurement by its own weight by considering the characteristics of the measurement sensor that requires a constant tension maintained in the axial direction. The size of the pipe was also reduced to minimize the possible effect of heat transfer on the steel surface. In addition, displacement measurement via video image processing was performed using a visual displacement camera to hedge against measurement failure, as shown in Fig. 3. The method adopted to realize video image processing involved estimating displacement based on the change in the pixel of the measurement position by time by saving the unit grid and measurement position from the same camera angle in pixel units in advance and then imaging the recorded video. 


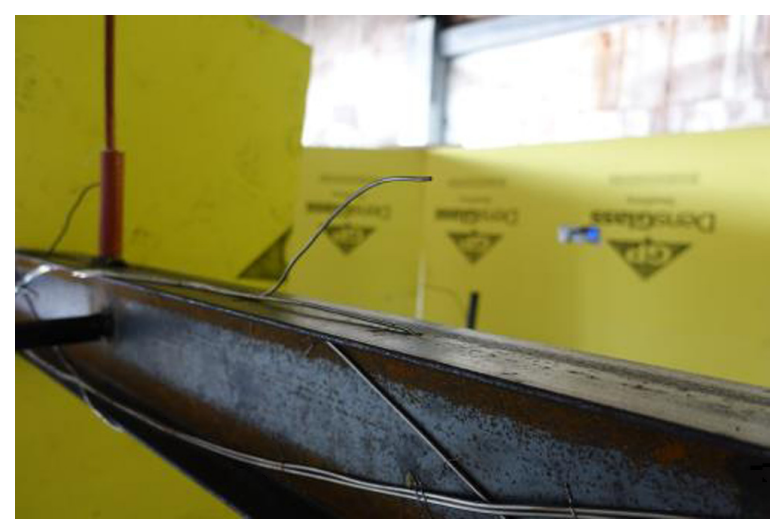

(a) Thermocouple for gas temperature measurement

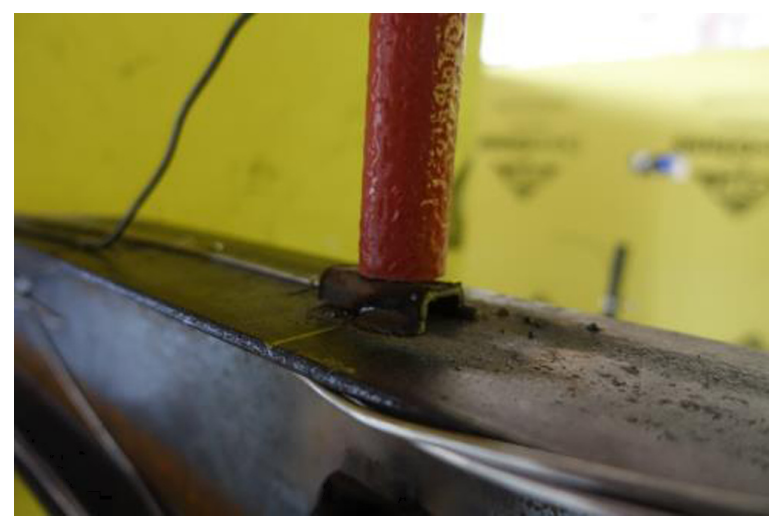

(c) Instrumentation for vertical displacement measurement

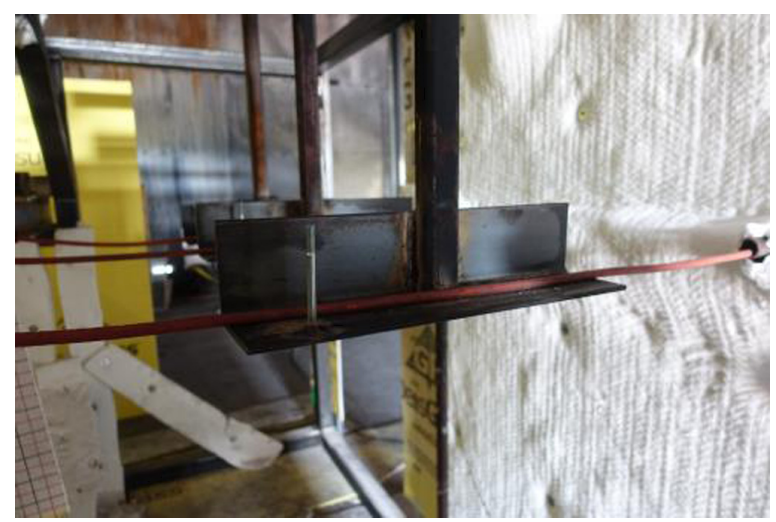

(e) Support for horizontal displacement measurement

Fig. 6 Measurement instrumentation for fire experiment

Finally, the displacement of the support in the longitudinal direction of the specimen was determined immediately after the experiment using a laser displacement sensor as the support can be deformed by the reaction force of the specimen, which expands in the longitudinal direction owing to the influence of high temperature.

\section{Burner Fire Experiment Result}

Fig. 7 and Figs. 9-12 presents the time history results obtained from the burner fire experiment for gas temperature, steel surface temperature, vertical displacement, and horizontal displacements and these results were analyzed, respectively.

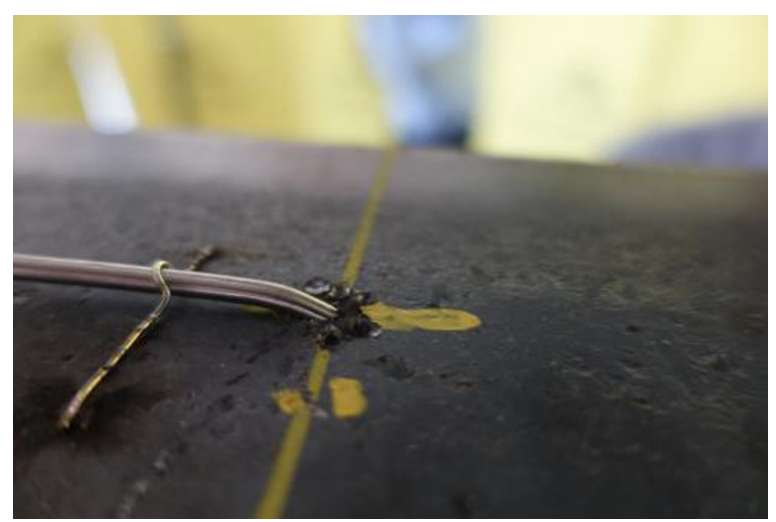

(b) Thermocouple for steel surface temperature measurement

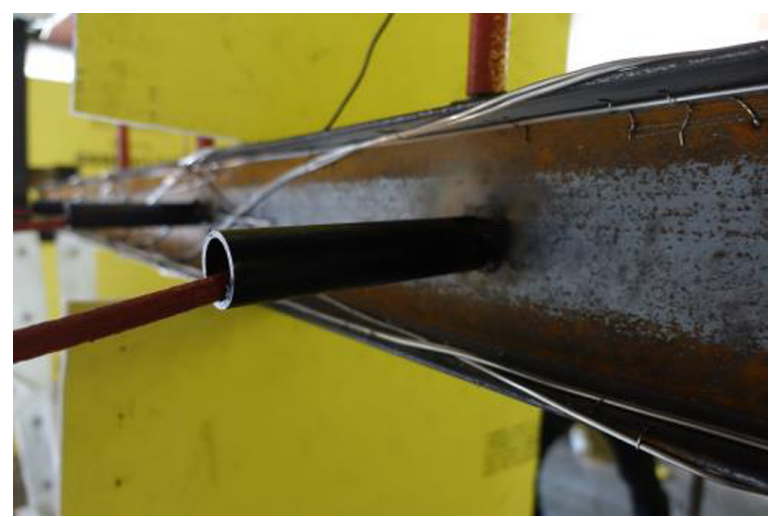

(d) Instrumentation for horizontal displacement measurement

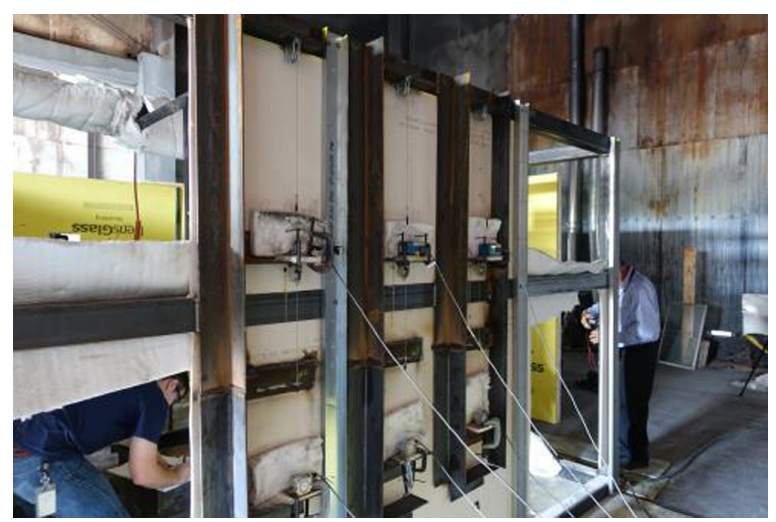

(f) String potentiometer for displacement measurement

\subsection{Gas Temperature}

Fig. 7 presents the measurement results of gas temperature obtained at a position $100 \mathrm{~mm}$ away from the upper flange of the specimen in the vertical direction while the gas temperature for each measurement position is presented in Appendix Fig. A1. The highest gas temperature was measured at GT5 (approximately $800^{\circ} \mathrm{C}$ ), which is $500 \mathrm{~mm}$ away from the center of the specimen in the longitudinal direction, and this is apparently attributable to the observed flame movement illustrated in Fig. 8. The flame moves from the center of the burner to the left, as shown in Figs. 8(a), (c), (d), and (e), and accordingly, gas temperature was determined to be high at GT2 and GT3 as shown in (1), (3), (4), and (5) in Fig. 7, and at GT5 and GT6, 


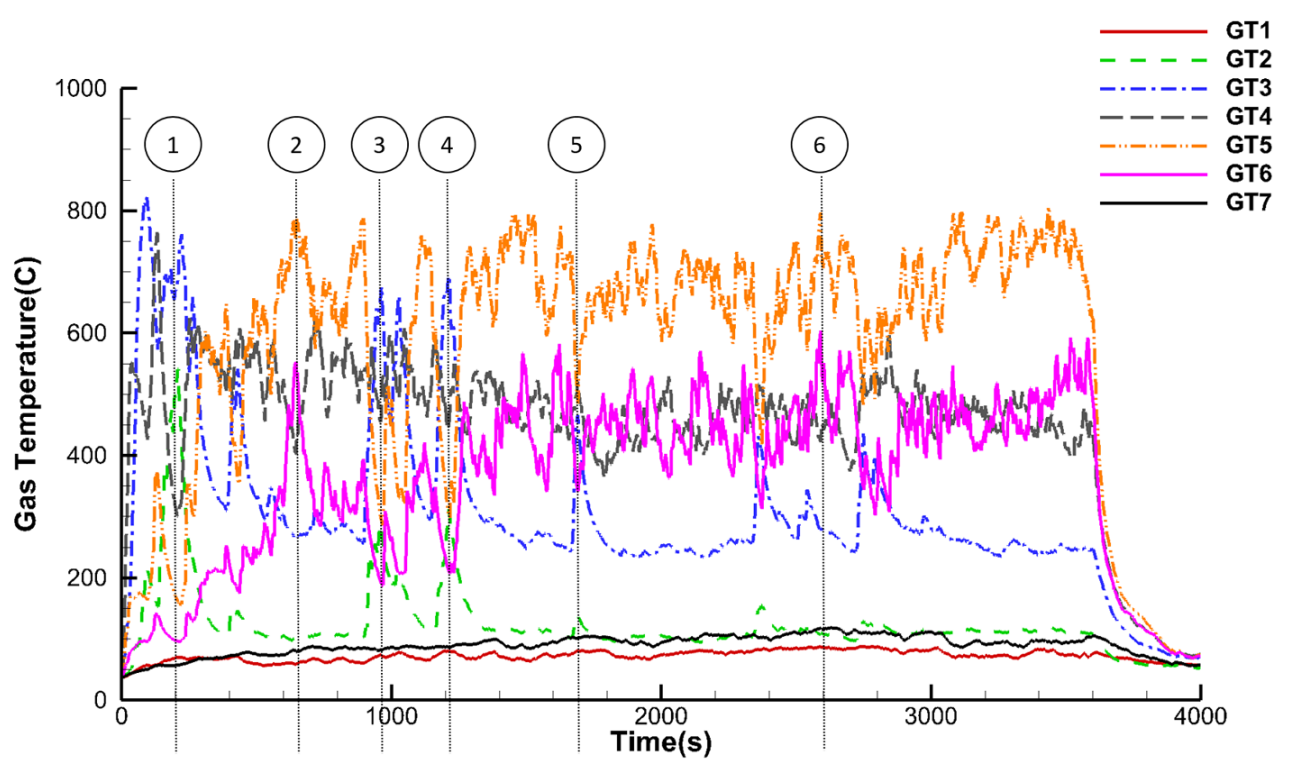

Fig. 7 Gas temperature results of test specimen

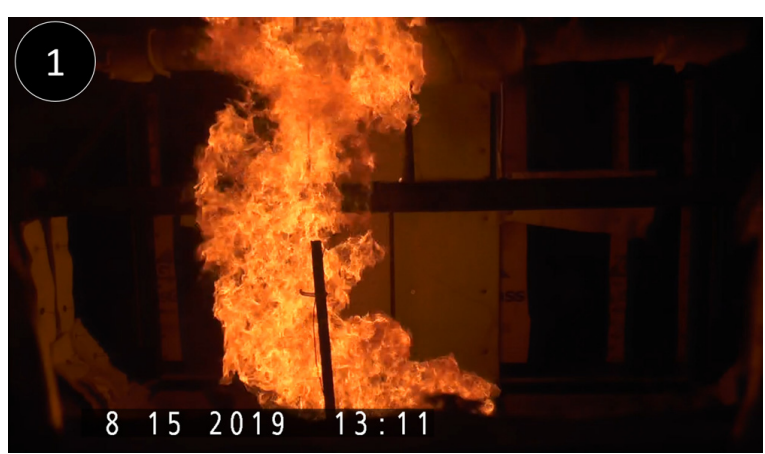

(a) $200 \mathrm{~s}$

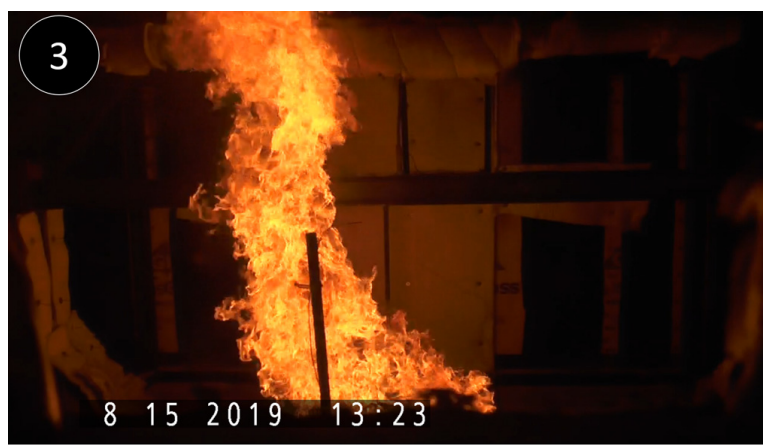

(c) $962 \mathrm{~s}$

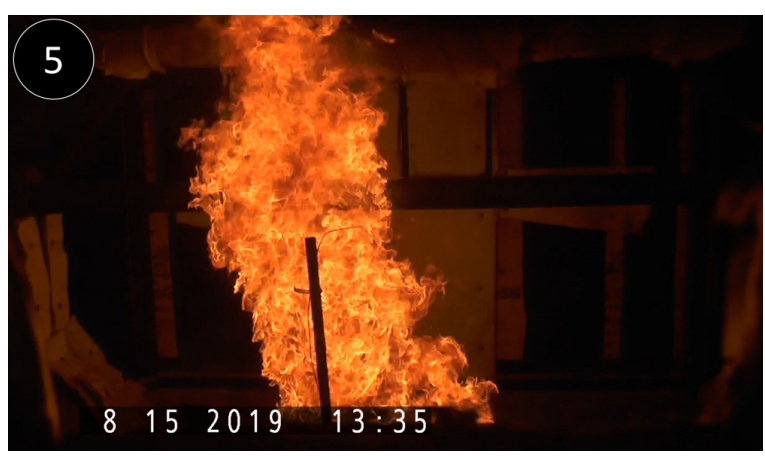

(e) $1,690 \mathrm{~s}$

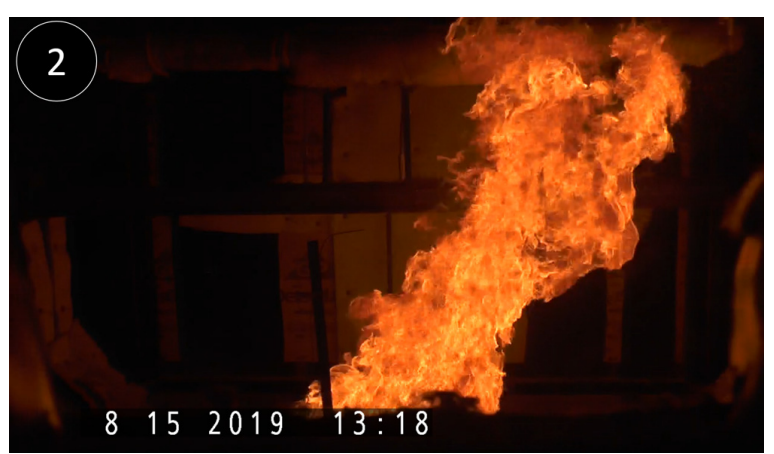

(b) $650 \mathrm{~s}$

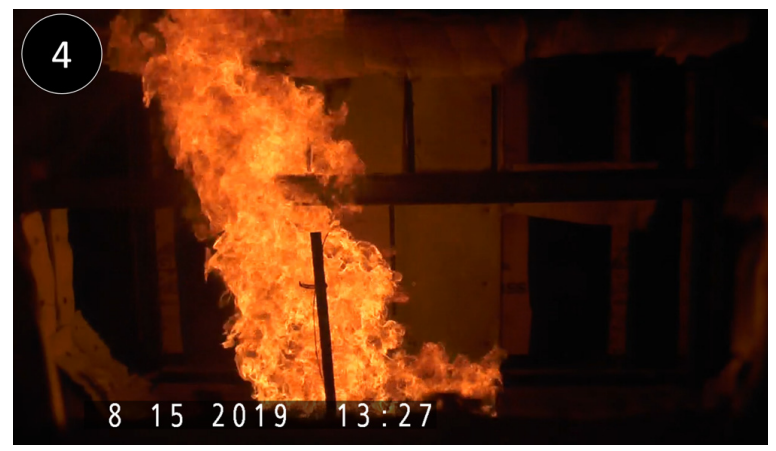

(d) $1,210 \mathrm{~s}$

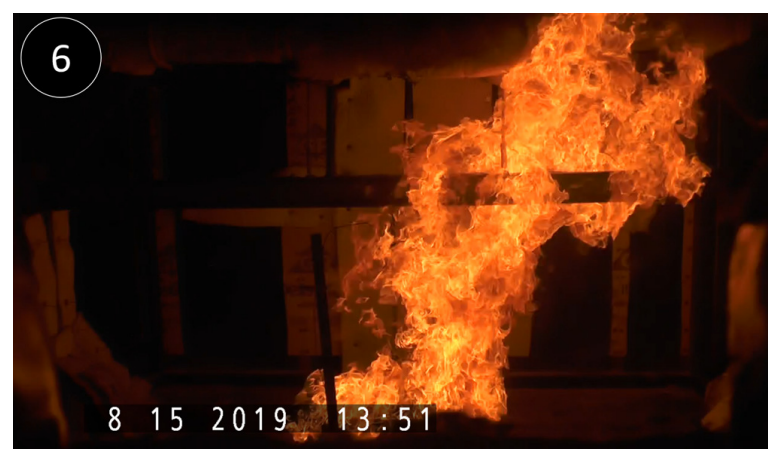

(f) $2,600 \mathrm{~s}$

Fig. 8 Experimental scene for observing flame movement 
which were installed symmetrically around GT4, it was determined to be low.

The opposite case can be observed in Figs. 8(b) and (f), and in (2) and (6) of Fig. 7. An irregular flame movement was observed although the experiment was conducted in an enclosed space, including wind shields walls. This is presumed to be owing to the air flow that was affected by the asymmetrically installed wind shield walls, as well as the fuel that was not uniformly distributed in the sand flowing into the burner, thereby triggering uneven combustion. The lowest temperature of approximately $80^{\circ} \mathrm{C}$ was measured at GT1, which was $2,000 \mathrm{~mm}$ away from the center of the specimen in the longitudinal direction.

\subsection{Steel Surface Temperature}

The results of the steel surface temperature of the specimen are divided into upper and lower flanges, as presented in Figs. 9 and 10, and the average and maximum temperatures at each position are as summarized in Table 1. The average temperature is the average of the temperatures measured during the combustion time of 0-3,600 s. In addition, steel surface temperature at each measurement position is presented in Appendix Fig. A2.

In the upper flange case, the highest temperature (average: $610^{\circ} \mathrm{C}$, maximum: $734^{\circ} \mathrm{C}$ ) was measured at ST5, which was $500 \mathrm{~mm}$ away from the center of the specimen. This result follows the trend of the gas temperature distribution. The longitudinal temperature distribution appeared to be symmetrical around the ST5, and the overlapping temperature histories of ST3 and ST5, which were symmetrical around the burner's position, indicate a significant influence on the movement of the flame illustrated in Fig. 8.

In the lower flange case, the highest temperature (average: $674^{\circ} \mathrm{C}$, maximum: $740^{\circ} \mathrm{C}$ ) was measured at ST15, which was approximately $200 \mathrm{~mm}$ away from the center of the specimen, and a high temperature (average: $594^{\circ} \mathrm{C}$, maximum: $738^{\circ} \mathrm{C}$ ) was also measured at ST16, which was approximately $700 \mathrm{~mm}$ away from the center of the specimen. Similar to the upper flange case, this result follows the gas temperature distribution trend, and it was determined that the temperature

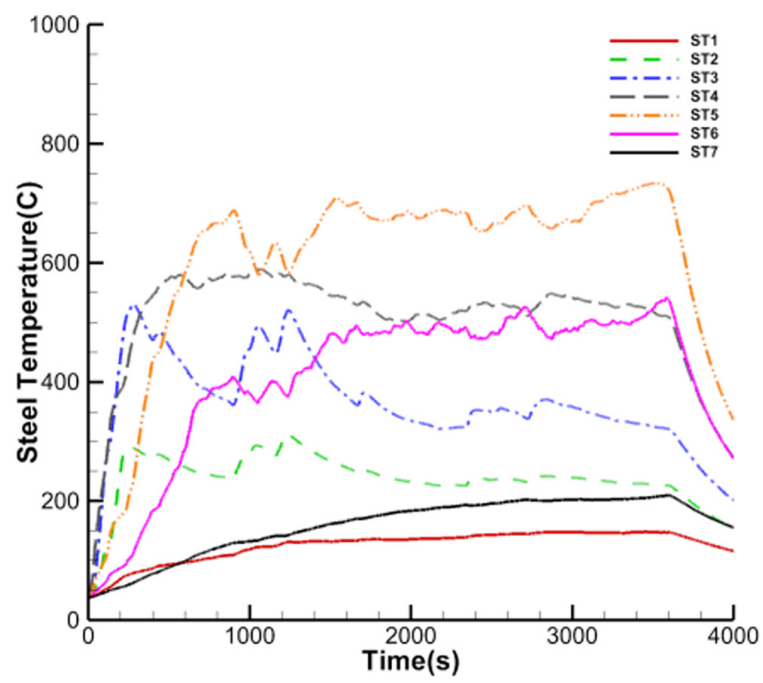

Fig. 9 Steel surface temperature results of upper flange

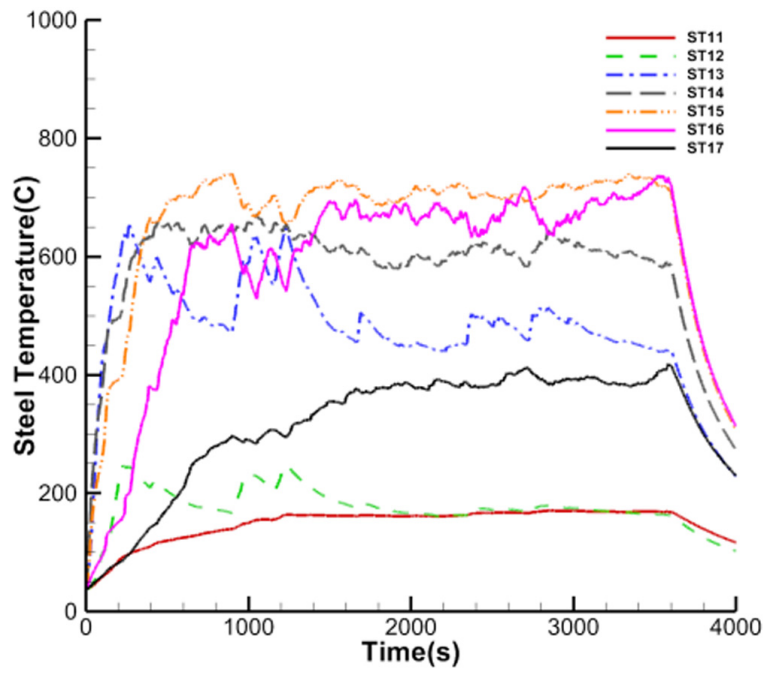

Fig. 10 Steel surface temperature results of lower flange

Table 1 Average and maximum steel surface temperature results of specimen

\begin{tabular}{lccccccc}
\hline & ST1 & ST2 & ST3 & ST4 & ST5 & ST6 & ST7 \\
\hline Avg. Temp. $\left({ }^{\circ} \mathrm{C}\right)$ & 125 & 243 & 377 & 521 & 610 & 410 & 157 \\
Max. Temp. $\left({ }^{\circ} \mathrm{C}\right)$ & 148 & 313 & 531 & 589 & 734 & 542 & 210 \\
\hline & ST11 & ST12 & ST13 & ST14 & ST15 & ST16 & ST17 \\
\hline Avg. Temp. $\left({ }^{\circ} \mathrm{C}\right)$ & 149 & 180 & 495 & 602 & 674 & 594 & 318 \\
Max. Temp. $\left({ }^{\circ} \mathrm{C}\right)$ & 171 & 247 & 653 & 673 & 740 & 738 & 418 \\
\hline
\end{tabular}

distribution of the lower flange, which is relatively close to the fire source, was more influenced by the flame movement.

In general, lower temperature distribution is exhibited as the distance increases in the longitudinal direction from the position 500 $\mathrm{mm}$ to the right from the center of the specimen. However, because the temperature of ST12, located between ST2 and ST3 in the longitudinal direction, was measured lower than ST17, it was determined that the steel surface temperature data were reasonable except the data from this sensor.

\subsection{Displacement}

The displacement history and deformation shape of the specimen in the vertical and horizontal directions are illustrated together in Figs. 11 -13 , and the displacement for each the measurement position is presented in Appendix Fig. A3. Visuals $\mathrm{Z}$ and $\mathrm{Y}$ in the graph represent the vertical and horizontal displacements, respectively, that are measured via video image processing.

Regarding the final displacement in the vertical direction of the specimen at 3,600 s, which occurred at the end of the fire experiment, approximately $9 \mathrm{~mm}$ (maximum: $13.8 \mathrm{~mm}$ ) of deflection was measured at ZD3, which was $500 \mathrm{~mm}$ away from the center of the specimen. In contrast, the displacement within approximately $4 \mathrm{~mm}$ (maximum: $9.6 \mathrm{~mm}$ ) was measured at $\mathrm{ZD} 2$, which is at the center of the specimen while the displacement within approximately $3 \mathrm{~mm}$ (maximum: $8.3 \mathrm{~mm}$ ) was measured at $\mathrm{ZD1}$, which was $500 \mathrm{~mm}$ to the 
left of the specimen center. These displacements are invisible to the naked eye. A similar trend was observed when comparing the displacement results via video image processing with the displacement results obtained via a string potentiometer. The largest displacement was determined at $\mathrm{ZD} 3$, the position at which the steel surface temperature was the highest, and the overall downward behavior in the vertical direction shifted upwards after 150-350 s.

The maximum final displacement in the horizontal direction of the specimen of approximately $20 \mathrm{~mm}$ was measured at YD2, at the center of the specimen. Meanwhile, the displacements of 10 and $12 \mathrm{~mm}$ were measured at YD1 and YD3, respectively, which were $500 \mathrm{~mm}$ away from the center of the specimen in the longitudinal direction. The largest displacement was measured at the center of the specimen. Between YD1 and YD3, a larger displacement measured at YD3, where a relatively higher steel surface temperature was measured. Regarding the behavior of the specimen, deflection (-) to the back was observed before approximately $400 \mathrm{~s}$ when the specimen was viewed from the front while forward deflection $(+)$ was observed after 400 seconds. In general, the displacement in the horizontal direction was

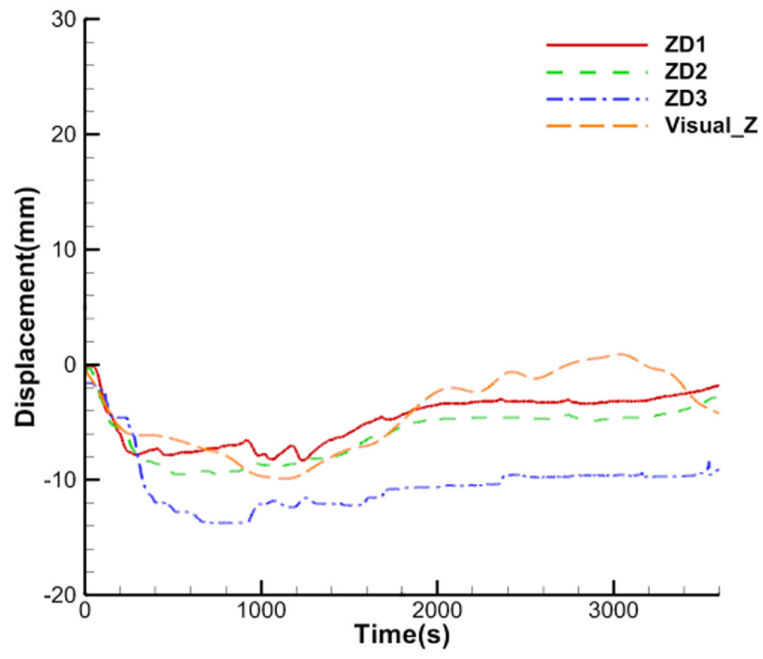

Fig. 11 Vertical displacement results of specimen

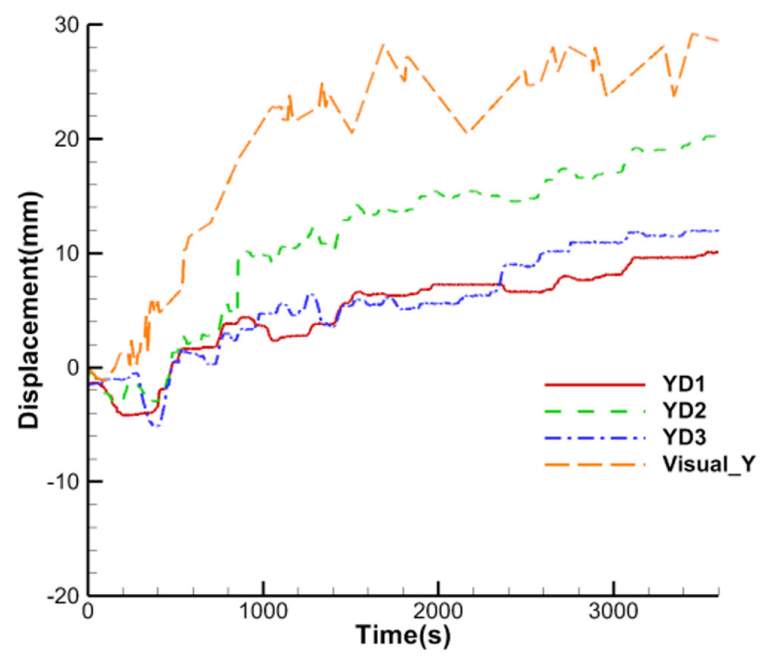

Fig. 12 Horizontal displacement results of specimen

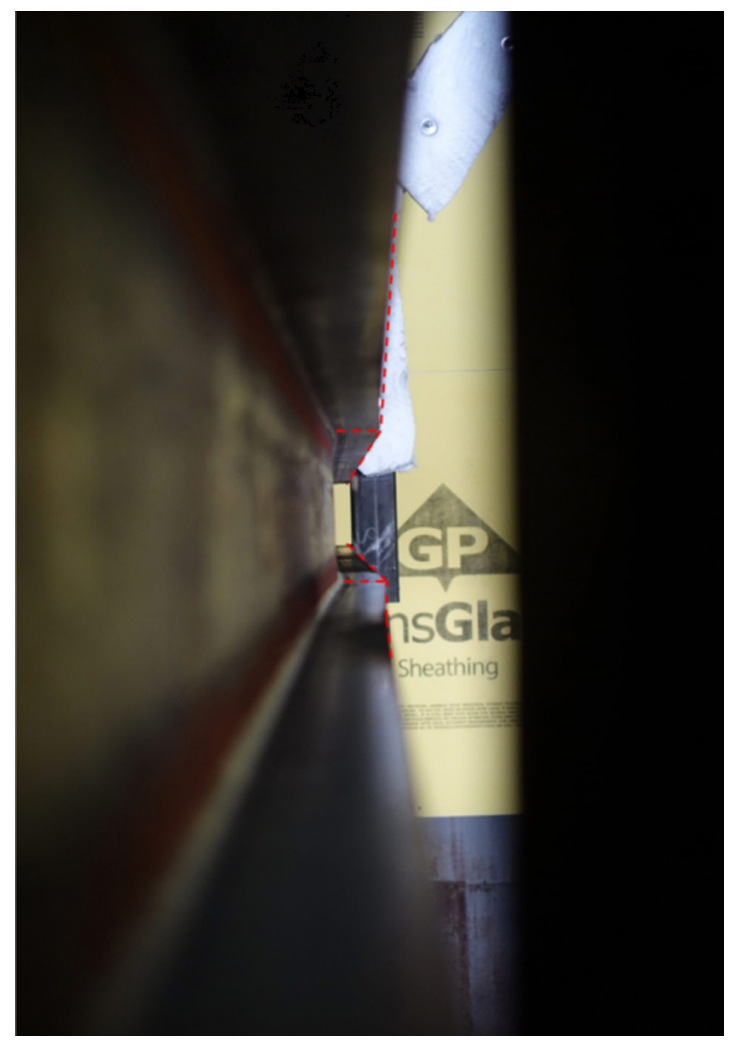

Fig. 13 Deformed shape of specimen

more significant than that in the vertical direction. It is inferred that this phenomenon is owing to the deformation in the horizontal direction with weak stiffness according to the geometric shape of the $\mathrm{H}$-beam cross section because the reaction force, as the displacement of the specimen expanding in the longitudinal direction, is surrounded by the boundary condition of fixed ends, which is similar to the deformation of a beam under a compressive load in the axial direction. In addition, only elastic deformation was observed in the vertical direction, and a permanent deformation of approximately $20 \mathrm{~mm}$ was observed in the horizontal direction, when displacement was measured after the fire was extinguished naturally at the end of the experiment, as illustrated in Appendix Fig. A3. Finally, although the horizontal displacement differs significantly more than the vertical displacement when comparing the displacement result via video image processing with the displacement result obtained by the string potentiometer, a similar trend was exhibited overall with video image measurements. The amount of deformation to the support itself, which was determined using a laser displacement sensor immediately after the end of the experiment, was approximately $10 \mathrm{~mm}$.

\section{Conclusion}

In this study, a fire experiment was conducted on an H-beam, a representative structural reinforcement for offshore structures, to obtain data for validating the thermal-structural analysis technology used in fire safety assessment of offshore structures. Regarding the experimental condition, an experiment was conducted by 
implementing the boundary condition of fixed ends without mechanical load to observe the effect of pure thermal load by $1.8 \mathrm{MW}$ burner fire. The gas temperature was measured by positioning the Inconel-sheathed grounded-junction type "K" thermocouple at 7 points, $100 \mathrm{~mm}$ away from the upper flange of the specimen, and the steel surface temperature distribution of the specimen in the horizontal and vertical directions was observed by installing the thermocouples equal to the gas temperature at 17 points of the upper flange, web, and lower flange. In addition, the structural behavior of the specimen under the fire load was investigated by measuring vertical and horizontal displacements with a string potentiometer. Furthermore, displacement measurement via video image processing was performed hedge against the failure of the displacement measurement. The experimental results and considerations are summarized as follows:

(1) The gas temperature near the specimen (9 points), steel surface temperature (17 points), vertical displacements, and horizontal displacements of the specimen (6 points) under the fire load were measured during the flame exposure for 3,600 s.

(2) The highest temperature (approximately $800^{\circ} \mathrm{C}$ ) was measured at GT5, which was $500 \mathrm{~mm}$ away from the center of the specimen in the longitudinal direction, and the general gas temperature distribution tended to decrease as the distance from the center of GT5 increased in the longitudinal direction.

(3) The highest gas temperature was observed at GT5, which was $500 \mathrm{~mm}$ to the right from the center of the specimen, and not at GT4 located in the center of the specimen or closest to the burner because the movement of the flame observed during the experiment was very significant, and the overall steel surface temperature measurement results obtained also followed this trend. The highest steel surface temperature (average: $610^{\circ} \mathrm{C}$, maximum: $734^{\circ} \mathrm{C}$ ) was measured at ST5, $500 \mathrm{~mm}$ away from the center of the specimen in the upper flange case, and the highest temperature (average: $674^{\circ} \mathrm{C}$, maximum: $740^{\circ} \mathrm{C}$ ) was measured at ST15, approximately $200 \mathrm{~mm}$ away from the center of the specimen in the lower flange case.

(4) Regarding the maximum final displacement in the vertical direction of the specimen under the fire load, a deflection of approximately $9 \mathrm{~mm}$ was measured at ZD3, $500 \mathrm{~mm}$ to the right from the center of the specimen, and the maximum final displacement in the horizontal direction was determined to be approximately $20 \mathrm{~mm}$ in YD2, which is at the center of the specimen. In general, the displacement in the horizontal direction was more significant than that in the vertical direction, which is inferred to be owing to the deformation in the horizontal direction with weak stiffness according to the geometric shape of the H-beam cross section.

In this study, we obtained the gas temperature, steel surface temperature, and displacement history in the time domain that can be used to verify the thermal-structural analysis technology of ship and offshore structures. In particular, the displacement history in the vertical and horizontal directions of the position directly exposed to the flame was obtained, and it was determined that the results were similar to that of the displacement measurement via video image processing. Consequently, it was determined that displacement can be stably measured via contact and non-contact methods even in harsh environments where high-temperature flames and smoke are mixed. However, the movement of the flame observed during the experiment was very significant, which significantly influenced the distributions of the gas and steel surface temperatures around the specimen. This phenomenon is inferred to be owing to combining the limitations of the experiment conducted in an open space, rather than in an enclosed space, where the amount of heat can be stably controlled, such as in a furnace, in addition to the uncertainty in the fire experiment as fuel was not evenly distributed in the sand filling the burner despite supplying sufficient fuel for the target heat release rate. In the future, the behaviour of structure under fire load will be analyzed using thermal-structural analysis which reflect flame movement observed in this study, as well as additional experiments to obtain data suitable for this analysis.

\section{Funding}

This research was supported by "Development of core technology for evaluating structural damage of hydroelasticity-based offshore structures in consideration of uncertainty (1/5) [PES3490]", which is a major project in Korea Research Institute of Ships and Ocean Engineering, and we are grateful for the support in form of the research fund.

\section{References}

Choe, L.Y., Ramesh, S., Zhang, C., \& Gross, J.L. (2016). The Performance of Structural Steel Beams Subject to a Localized Fire. In $9^{\text {th }}$ International Conference on Structures in Fire, Princeton University, USA, 392-399.

Cong, S., Liang, S., \& Dong, W. (2005). Experimental Investigation of Behavior of Simple Supported Steel Beams Under Fire. Journal of Southeast University (Natural Science Edition), 35, 66-68.

Hodges, J.L., Rippe, C., Case, S.W., \& Lattimer, B.Y. (2016). Thermographic Digital Image Correlation (TDIC) Measurements of Mechanically-Loaded Structures. In 9th International Conference on Structures in Fire, Princeton University, USA, 811-818.

Kim, J.H. (2014). A New Procedure for Fire Structural Assessment of Offshore Installations (Ph.D. thesis). Pusan National University, Busan, Korea.

Kim, S.J., Lee, J., Kim, S.H., Seo, J.K., Kim, B.J., Ha, Y.C., ... Sohn, J.M., (2017). Nonlinear Structural Response in Jet Fire in Association with the Interaction Between Fire Loads and Timevariant Geometry and Material Properties. Ocean Engineering, 144, 118-134. https://doi.org/10.1016/j.oceaneng.2017.08.028 
Rahm, M., Evegren, F., Johnson, E., \& Ringsberg, J.W. (2017). Structural fire integrity testing of lightweight multiple core sandwich structures, In Progress in the Analysis and Design of Marine Structures, Lisbon, Portugal, pp. 869-876.

Wainman, D.E., \& Kirby, B.R. (1988). Compendium of UK Standard Fire Test Data: Unprotected Structural Steel - 1. Rotherham, England: British Steel Corporation (BSC).

Wainman, D.E., Kirby, B.R., Tomlinson, L.N., Kay, T.R., \& Preston, R.R. (1990). The Behaviour of Unprotected Steel Floor Beams in the Standard Fire Resistance Test - Compendium of Predicted Temperature Profiles. Rotherham, England: British Steel Corporation (BSC).

\section{Author ORCIDs}

\section{Author name}

Ki, Min Suk

Park, Beom Jin

Lee, Kangsu

Park, Byoungjae

Fernandez, Kyle

Nho, In Sik
ORCID

0000-0001-6253-0531

$0000-0001-9729-4313$

$0000-0002-9505-6802$

$0000-0002-8943-1477$

0000-0003-2740-354X

0000-0003-1665-4968

\section{Appendix}

Appendix A Fire experiment results
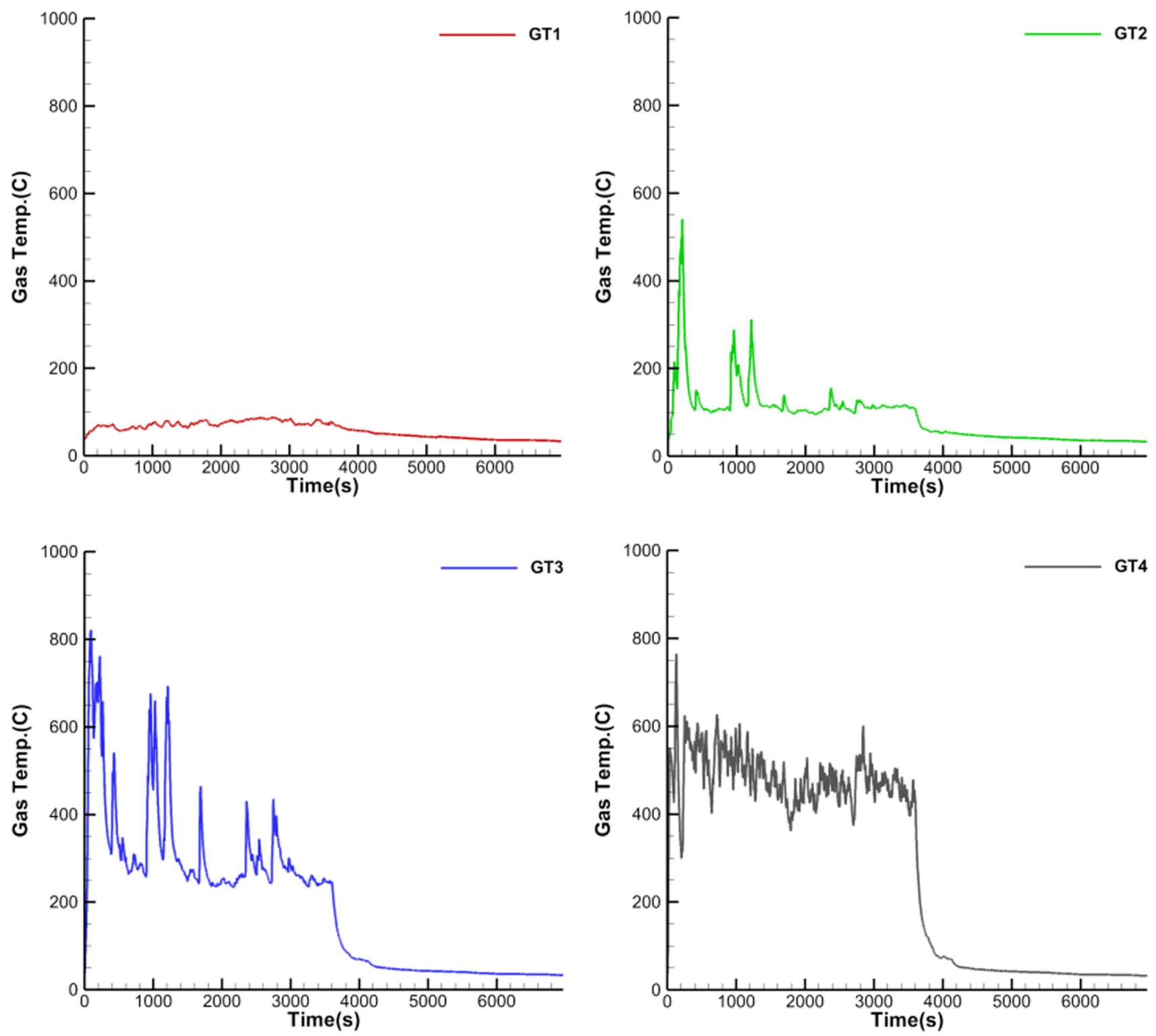

Fig. A1 Test results - gas temperature (continuation) 

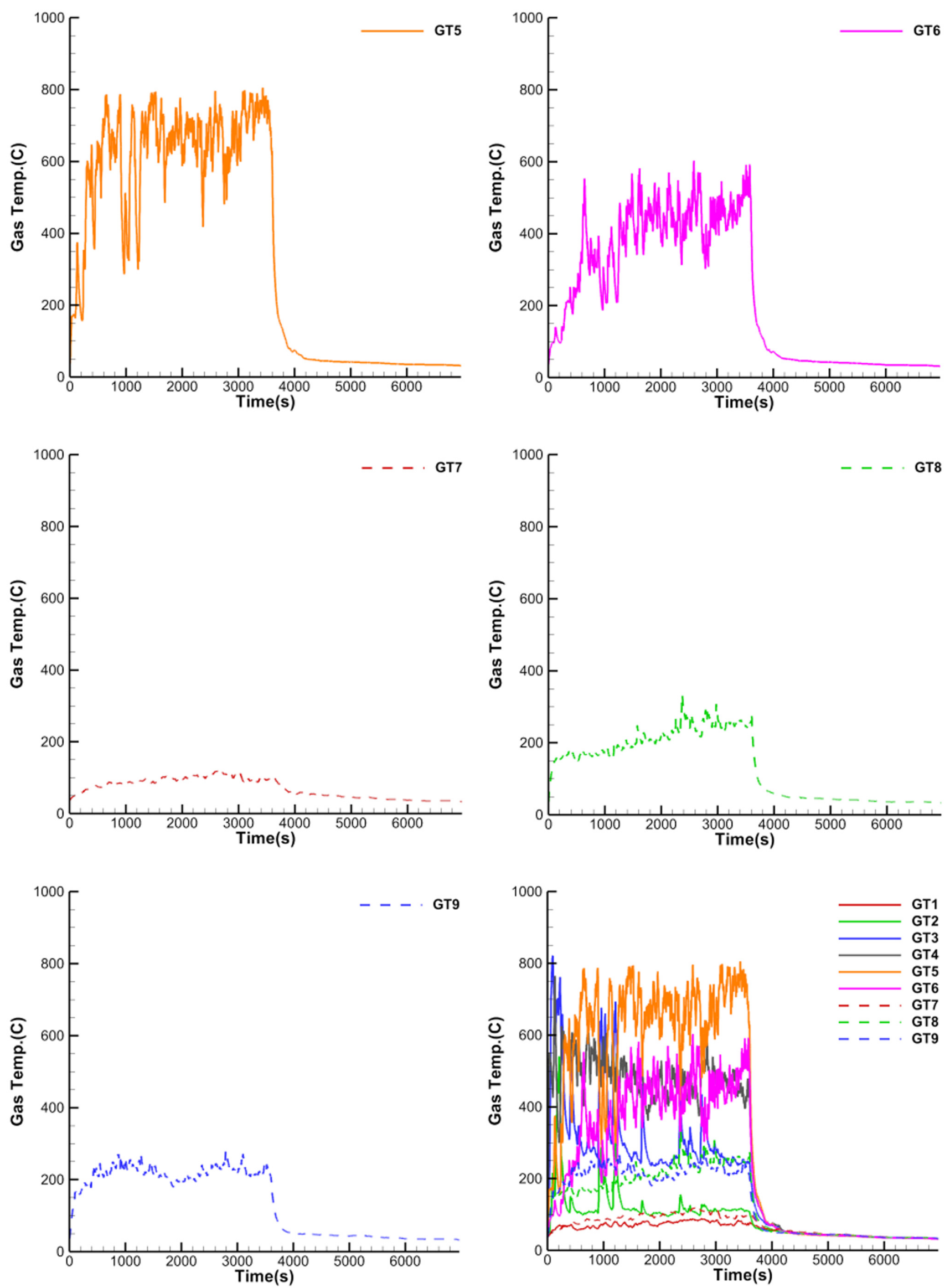

Fig. A1 Test results - gas temperature 

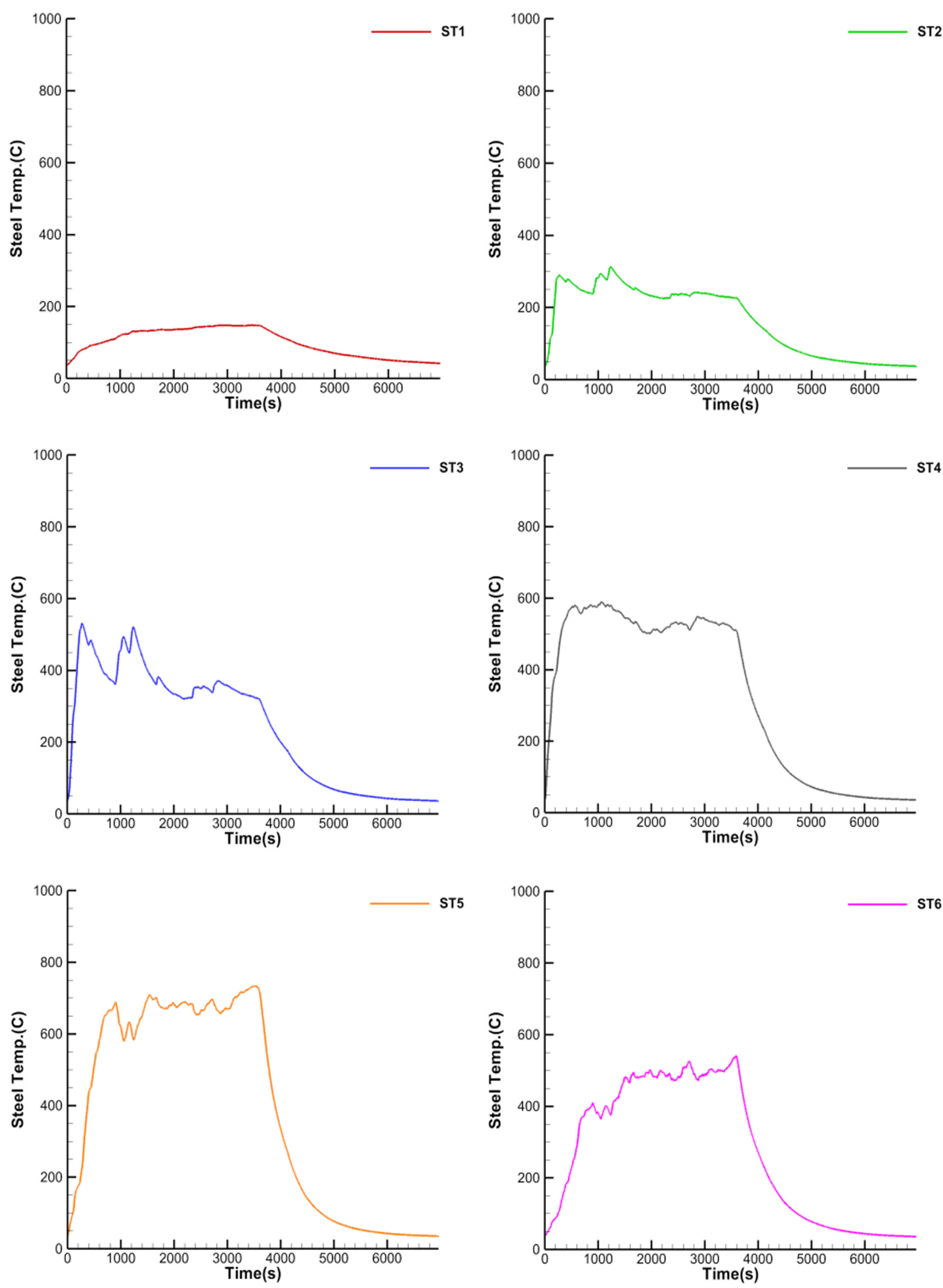

Fig. A2 Test results - steel surface temperature (continuation) 

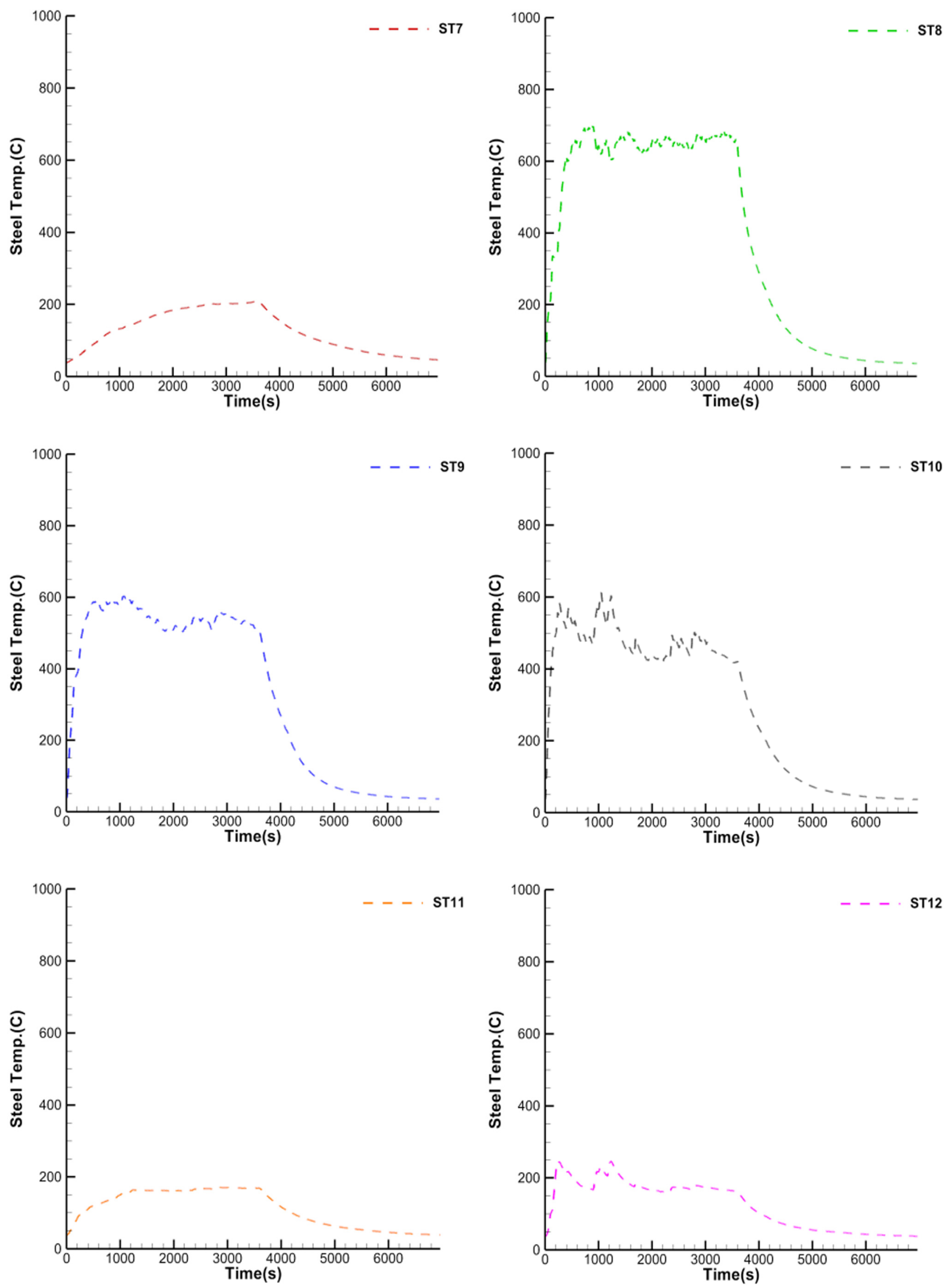

Fig. A2 Test results - steel surface temperature (continuation) 

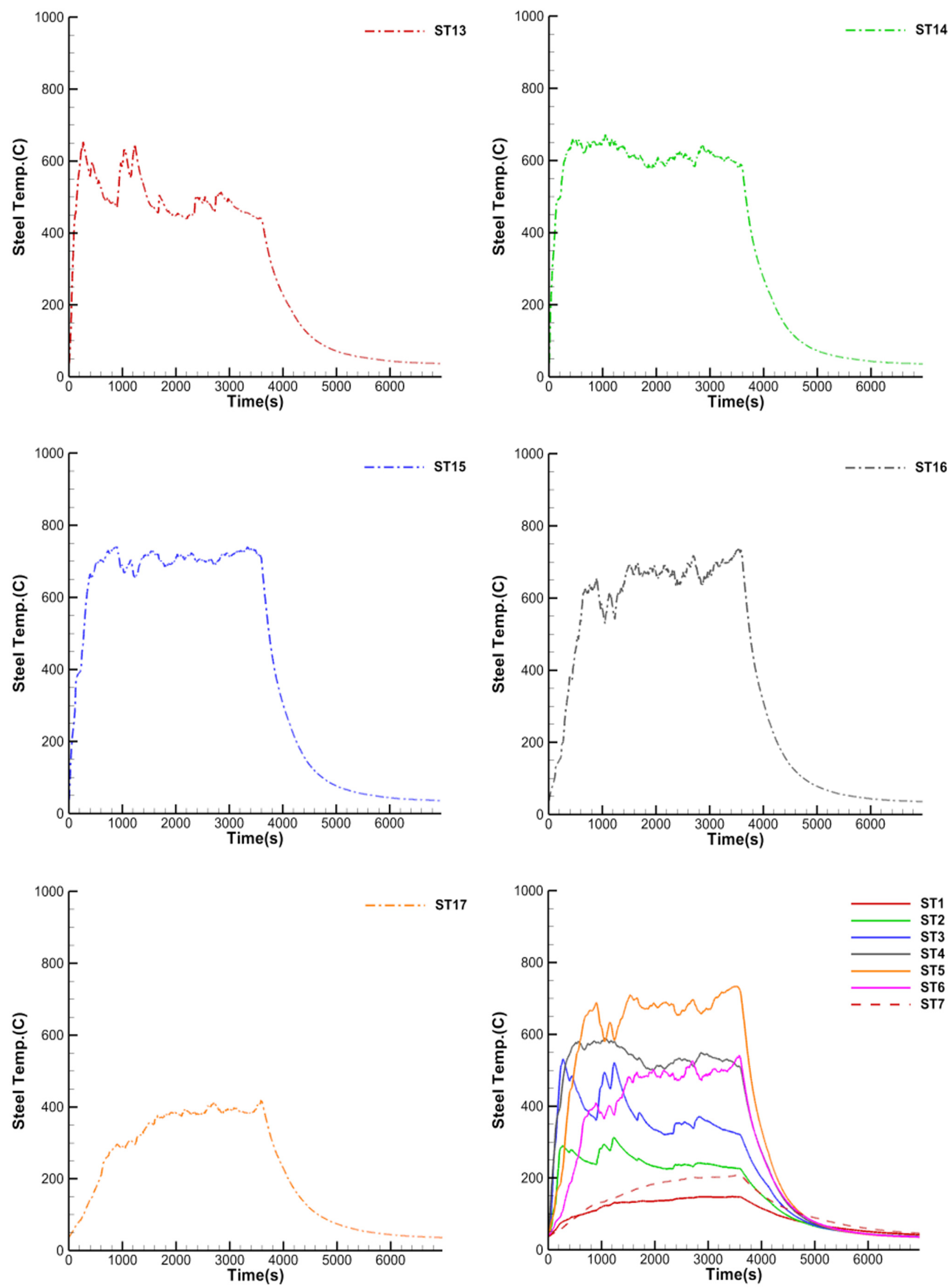

Fig. A2 Test results - steel surface temperature (continuation) 

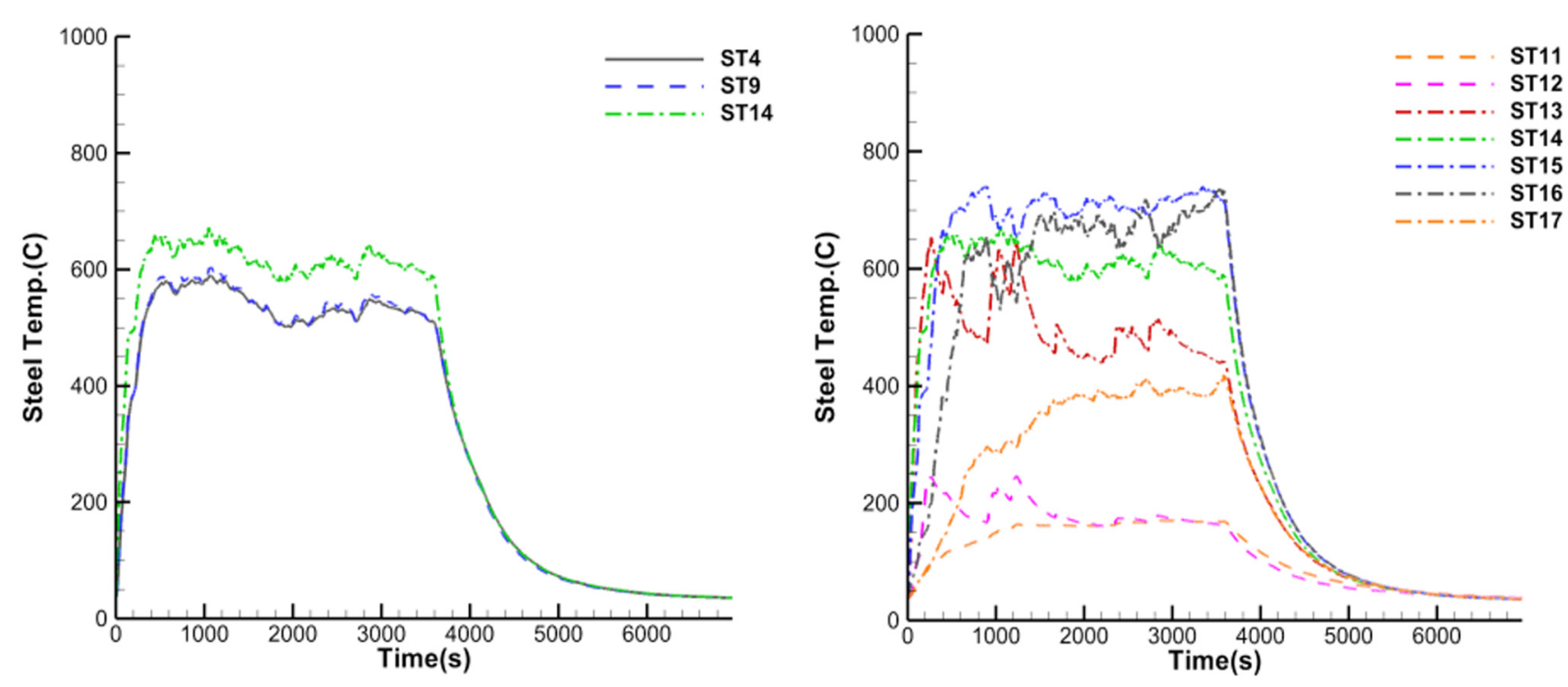

Fig. A2 Test results - steel surface temperature
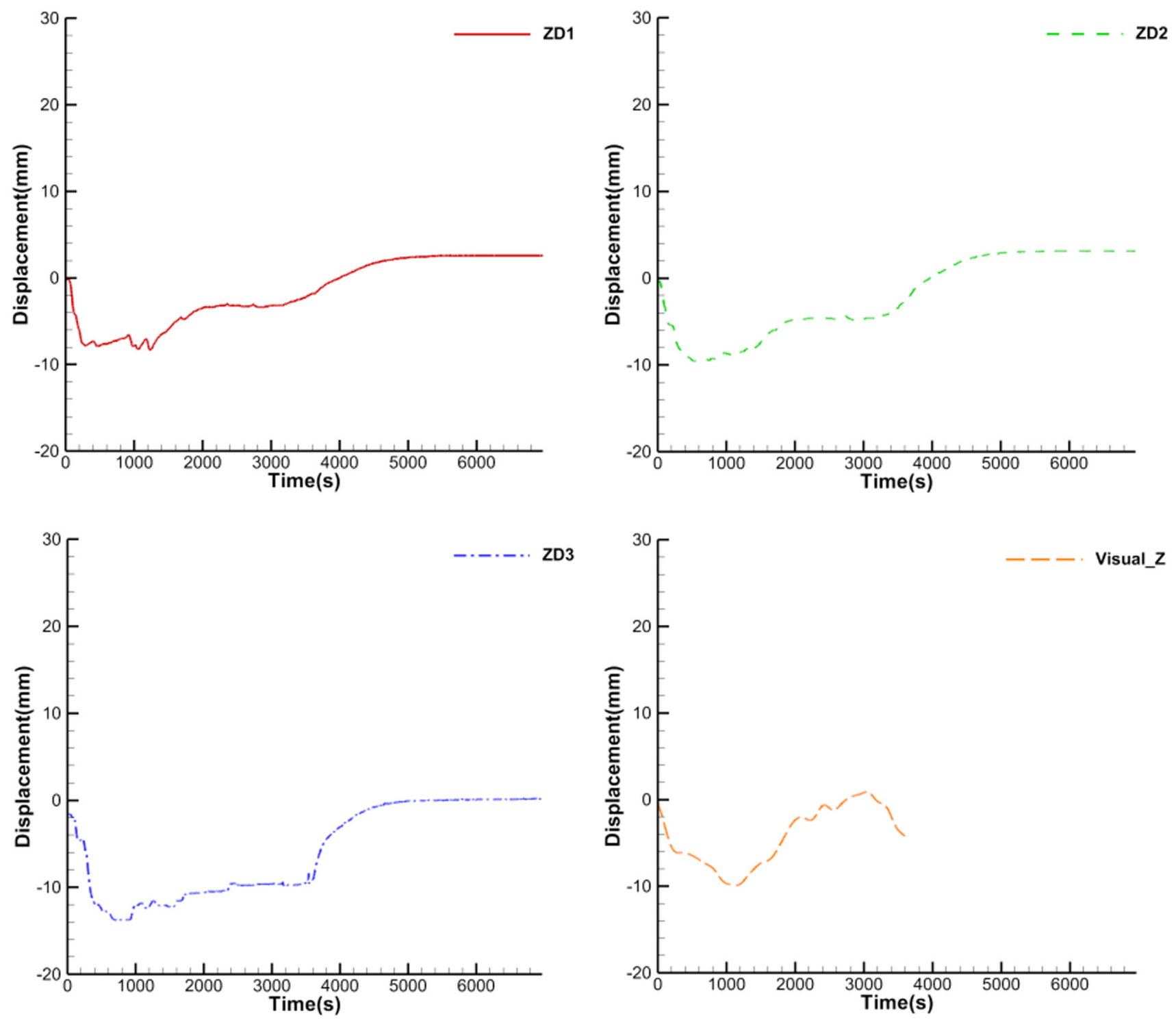

Fig. A3 Test results - displacement (continuation) 

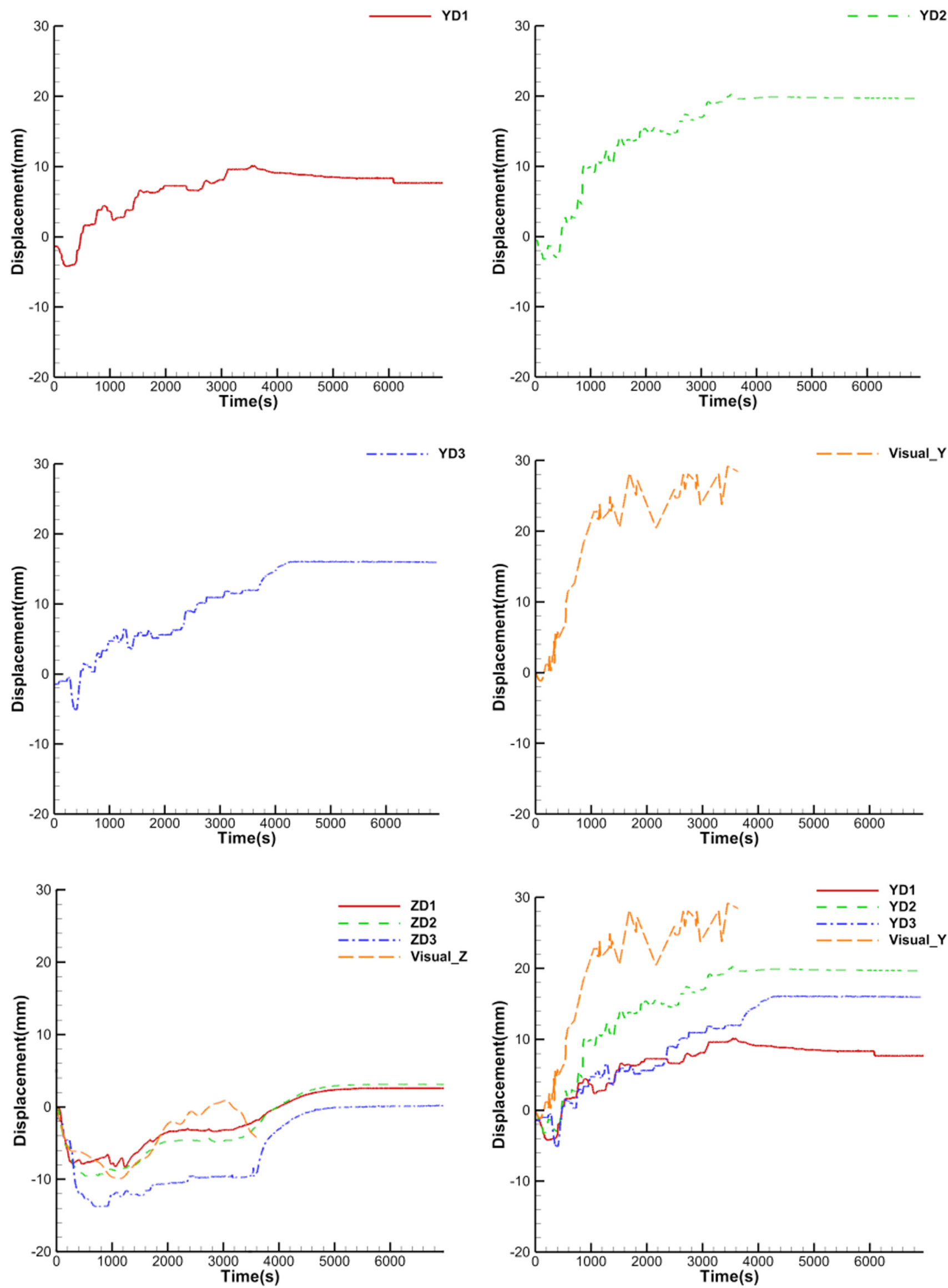

Fig. A3 Test results - displacement 